\title{
POSTERIOR URETHRAL VALVE- AN EVALUATION AND OUTCOME IN A TERTIARY CARE INSTITUTION
}

Amit Ray1, Purba Haldar², Durgaprasad Nanda3, Kartik Chandra Mandal', Amitava Sarkar5, Biswanath Mukhopadhyay ${ }^{6}$

${ }^{1}$ Assistant Professor, Department of Surgery, IPGME \& R, Kolkata.

${ }^{2}$ Assistant Professor, Department of Anaesthesiology, CNMC \& H, Kolkata.

${ }^{3}$ Postgraduate Student, Department of Surgery, IPGME \& R, Kolkata.

${ }_{4}^{4}$ Associate Professor, Department of Paediatric Surgery, Dr. B. C. Roy PGIPS, Kolkata.

${ }_{5}^{5}$ Professor, Department of Surgery, IPGME \& R, Kolkata.

${ }^{6}$ Consultant, Senior Paediatric Surgeon, Apollo Gleneagles Hospital, Kolkata.

\section{ABSTRACT}

\section{BACKGROUND}

Aims \& Objectives- Posterior urethral valve (PUV) is a common cause of lower urinary tract obstruction. Delay in the diagnosis and management leads to renal damage resulting in End stage renal disease (ESRD). This study analysed the following parameters: 1. The demographic profile of PUV patients. 2. Clinical profile and its relationship to age at diagnosis, renal function and Vesico Ureteral Reflux (VUR) and outcome.

\section{MATERIALS AND METHODS}

A total of 60 male children having urinary complaints with suspicion of PUV attending in OPD, emergency \& admitted in indoor were included in this study. Parameters studied included: a) Age at presentation b) Presenting features and severity c) Base line investigations including biochemical parameters and imaging, d) Time taken for the procedure, e) Postoperative complications, f) Postoperative investigations including biochemical parameters and imaging.

\section{RESULTS}

A total of 60 children managed for PUV were studied. 54 children underwent cystoscopic valve fulguration. Of the remaining 6 children, who had primary vesicostomy elsewhere and subsequently referred to us, cystoscopic valve fulguration followed by vesicostomy closure was done in the same sitting. Of the 60 children, 11 had normal urinary stream, 36 had nocturnal enuresis and 13 had daytime frequency for a mean duration of 6 months and nocturnal enuresis for 3 months. VUR initially seen in 28 patients. Regressed completely at a mean duration of 3 months in 12 patients. Group IV-V VUR was seen in 8 patients ( 6 bilateral), which regressed completely by 6 months in 4 patients. In the non-VUR, Hydroureteronephrosis (HDU) patients (32 patients) slow but unobstructed drainage was persistent in 4 patients at 1 year, 6 were poorly functioning kidney, and 8 children had abnormal creatinine at follow-up. 6 required a second fulguration while 2 required urethral dilatation for stricture following which all parameters improved. We did not encounter any major intra or post-operative complications excepting three neonates who were very low birth weight and had birth asphyxia with compromised renal functions. Two of them died even after valve ablation. Two were lost to follow-up.

\section{CONCLUSION}

This study represented an opportunity to evaluate the follow-up of children with PUV seen at a single centre. Early endoscopic valve fulguration is the best initial modality of management in majority of children with PUV and this gives superior results to diversion

\section{KEYWORDS}

Posterior Urethral Valve, Renal Function, Evaluation, Management, Outcome.

HOW TO CITE THIS ARTICLE: Ray A, Haldar P, Nanda D, et al. Posterior urethral valve- an evaluation and outcome in a tertiary care institution. J. Evolution Med. Dent. Sci. 2017;6(1):14-18, DOI: 10.14260/Jemds/2017/5

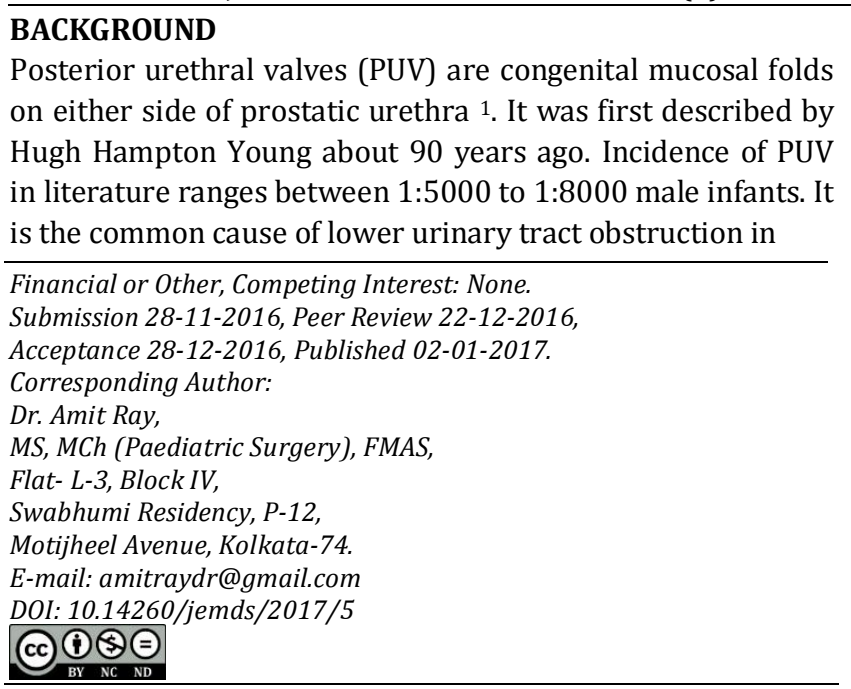
male babies.2,3 So presentation of PUV may vary from very subtle to very severe urinary tract obstruction to an extent that may not be compatible with postnatal life ${ }^{4}$. The degree of obstruction depends on the configuration of the obstructive membrane within the urethra and varies in severity. In utero obstruction may results in varying degrees of dysplastic kidneys, bilateral hydroureteronephrosis, thickened hypertrophied noncompliant urinary bladder and pulmonary hypoplasia due to oligohydronephrosis. ${ }^{4,5,6}$ The severe cases present with renal failure, Respiratory failure requiring Intensive care unit care and close monitoring. Milder cases may present even in adult life.

PUV is the second most common cause of CRF in children. In one study, it was reported in $23 \%$ of cases $^{7,8}$ while it was seen in $7 \%$ cases in Guys' hospital, UK series. ${ }^{8}$ 


\section{Aims and Objectives}

PUV is a common cause of lower urinary tract obstruction. Delay in the diagnosis and management leads to renal damage resulting in End Stage Renal Disease (ESRD). This study analysed

1. The demographic profile of PUV patients and

2. The clinical profile of patients and its relationship to age at diagnosis, renal function, vesico-ureteral reflux (VUR), associated anomalies and finally the outcome.

\section{MATERIALS AND METHODS}

The study was conducted in a tertiary care institution. This was a descriptive study on patients from January 2011 to December 2014 with follow-up till June 2016. After obtaining valid consent and approval from the institutional ethical board, procedure was carried out. Study population included male children up to 12 years of age of all ethnic and religious groups from different socio economic status having urinary complaints with suspicion of PUV attending in OPD, Emergency and admitted in Indoor. All patients who presented with urinary complaints like dribbling of urine, poor stream, retention, dysuria, pulling at penis, urinary tract infection and renal failure were evaluated after detailed history and clinical evaluation.

Diagnosis was based on ultrasonography (USG) of urinary tract and voiding cystourethrography (VCUG). Sixty male children with PUV on voiding cystourethrogram (VCUG) were enrolled into the study. Study design was kept simple. It was a descriptive study. Parameters that were studied included: a) Age at presentation, b) Presenting features and severity, c) Base line investigations including Biochemical parameters and imaging, d) Time taken for the procedure, e) Postoperative complications and f) Outcomes in terms of improvement of post-operative symptoms, biochemical parameters, growth of the child improvement in USG grading of hydronephrosis, resolution of Vesico Ureteric Reflux (VUR) improvement in split renal function in diuretic isotope renogram.

\section{RESULTS}

Sixty six patients suspected of PUV were evaluated. Out of them 60 male patients with PUV on VCUG were selected for the study. Age ranges from 11 days to 3 year 5 months. Mean age 3 months 22 days. Eight (8) were suspected in antenatal period $(13 \%)$ on ultrasound showing bilateral hydronephrosis and large distended urinary bladder, later confirmed on VCUG after birth. Thirty one (31) patients (52\%) presented within neonatal period of life (within 28 days of life), sixteen (16) children (27\%) presented within one year ( 1 year) of life and 5 children $(8 \%)$ at the age group between 3 to 5 years.

Common clinical presentations were urinary complaints along with fever, anaemia and failure to thrive (table 1). Thirty two (32) patients (53\%) had abnormal renal function and twenty eight (28) children (47\%) had secondary VUR. The frequency of renal failure and VUR increased with age. Nearly all (except one) patient presenting after the age of six years had abnormal renal function and VUR (table 2 and 5).Urinary tract infection (common organism was E Coli) was found in forty three (43) patients. Among sixty (60) children, twenty eight (28) had associated vesico urethral reflux (VUR). Unilateral reflux was seen in sixteen (16) children.
Reflux was predominantly seen in the left side (Lt - 12, Rt -4). Bilateral reflux was seen in twelve (12) children (table 2 and 4).

The different grades of reflux were seen at presentation: a) Gr I-II: 14 children, b) Gr III: 6 children, c) Grade IV to V: 8 children. Grade I-III VUR regressed completely at a mean duration of 6 months in 20 patients. Down grading of Gr IV-V VUR to Gr II-III VUR seen in 4 patients. Persistent high grade reflux (VUR IV-V) with elevated creatinine value seen in 4 patients. Loop ureterostomy was performed for these children. In the non VUR, Hydroureteronephrosis (HDUN) patients (32 patients), slow but unobstructed drainage was persistent in 4 patients at 1 year, 6 were poorly functioning kidney and 4 died (Pulmonary insufficiency-2, metabolic abnormalities-2) in spite of all sorts of management.

Among 60 children, 4 had different varieties of anorectal malformation (Rectovesical fistula -1 , recto-bulbar fistula -2 , perineal fistula 1), 6 had distal penile hypospadias, 2 had undescended testis, both are on the left side (Canalicular variety) (Table 3).

54 children underwent cystoscopic valve fulguration. Of the remaining 6 children, who had primary vesicostomy elsewhere and subsequently referred to us, cystoscopic valve fulguration followed by vesicostomy closure was done in the same sitting. 6 children required a second fulguration.

For neonates, we used $4.5 \mathrm{~F}$ cystoscope \& Bugbee electrode and for older infants (More than 1 month) and children we used $6 \mathrm{~F} \& 9 \mathrm{~F}$ cystoscope \& resectoscope respectively. With the use of zero degree lenses, the leaflets are best visualised at 5 and 7 O'clock positions. Instruments are rotated $180^{\circ}$ to visualize and ablate the obstructing valve tissue at $120^{\prime}$ clock position.

We did not encounter any major intraoperative and postoperative complications excepting three neonates who were very low birth weight and had birth asphyxia with compromised renal functions. Two of them died even after valve ablation. Two neonates were lost to follow up. Maximum period of follow up was 5 years 3 months and minimum follow up period was 1 year 4 months. There is resolution of uraemia in 25 cases (42\%). Among which early presented cases were $18(30 \%)$ in number and late cases were $7(12 \%)$. Among the 28 patients presented with VUR resolution seen in 20 cases $(72 \%)$ Out of which 14 (50\%) were early and $6(22 \%)$ were presented late. Catching up of the normal growth (up to $30^{\text {th }}$ percentile) was observed in 34 cases $(57 \%)$. Among which early presented cases were 24 $(70 \%)$ and late cases were $10(30 \%)$ in number.

\section{Follow Up Protocol}

The principles of follow up are universal with the objectives being to maximize renal function, minimize urinary infection and renal scaring, assessment and management of voiding dysfunction with the aim of attaining total urinary continence and eventually arrange translation to adolescent and adult services.

Every month apart from clinical profile which includes assessment of height, weight, measurement of blood pressure, assessment of urinary stream, whether the bladder or kidneys are palpable or not, we performed the investigations as per the following protocol: 
Every Month- For first 6 months and there after,

Urine RE/ME

Urine $\mathrm{C} / \mathrm{S}$

Blood urea, Creatinine.

At 6 Weeks- Check cystoscopy for neonates where all three sites were not ablated simultaneously.

Every 3 months- For 1 st year and thereafter,

USG with renal biometry.

\section{At 6 and 12 Months}

1. MCU- If incomplete valve ablation is suspected \pm Check cystoscopy \pm Fulguration.

2. DMSA Scans and.

3. DTPA Scans (And thereafter yearly).

4. Urodynamic Study (If required).

\begin{tabular}{|c|c|c|}
\hline Presentation & No. of Patients & Percentage \\
\hline Recurrent Fever & 36 & 60 \\
\hline Anaemia & 22 & 37 \\
\hline Failure to thrive & 33 & 55 \\
\hline Dysuria & 21 & 35 \\
\hline Weak urinary stream & 24 & 40 \\
\hline Retention of urine & 15 & 25 \\
\hline Acidotic breathing & 11 & 18 \\
\hline Dribbling of urine & 17 & 28 \\
\hline Palpable bladder & 09 & 15 \\
\hline Palpable Kidney & 06 & 10 \\
\hline \multicolumn{2}{|c|}{ Table 1. Clinical Profile (n=60) } \\
\hline \multicolumn{2}{|l}{}
\end{tabular}

\begin{tabular}{|c|c|c|c|}
\hline Age & $\begin{array}{c}\text { No } \\
\text { Reflux }\end{array}$ & $\begin{array}{c}\text { Unilateral } \\
\text { VUR }\end{array}$ & $\begin{array}{c}\text { Bilateral } \\
\text { VUR }\end{array}$ \\
\hline Up to 28 days & 16 & 10 & 07 \\
\hline 28 days to 1 year & 06 & 04 & 04 \\
\hline 1-5 year & 02 & 02 & 01 \\
\hline \multicolumn{2}{|r|}{ Table 2. Relationship of Age and VUR } \\
\hline
\end{tabular}

\begin{tabular}{|c|c|c|}
\hline Anomalies & No. & Percentage \\
\hline VUR & 28 & 46 \\
\hline Distal penile hypospadias & 6 & 21 \\
\hline ARM ( All varieties) & 4 & 7 \\
\hline Undescended Testis (Left) & 2 & 3 \\
\hline \multicolumn{2}{|c|}{ Table 3. Associated Anomalies (n=40) } \\
\hline
\end{tabular}

\begin{tabular}{|c|c|c|}
\hline VUR & No. & Percentage \\
\hline Unilateral (Left) & 12 & 43 \\
\hline Unilateral (Bilateral) & 4 & 14 \\
\hline Bilateral & 12 & 43 \\
\hline Table 4. Incidence of VUR (n=28) \\
\hline
\end{tabular}

\begin{tabular}{|c|c|c|c|}
\hline Age & $\begin{array}{c}\text { No of patients } \\
\text { with Normal Renal } \\
\text { Function }\end{array}$ & $\begin{array}{c}\text { No of patients } \\
\text { with Abnormal } \\
\text { Renal Function }\end{array}$ & Total \\
\hline Prenatal & 2 & 6 & 8 \\
\hline $\begin{array}{c}\text { Up to } \\
\text { 28 Days }\end{array}$ & 13 & 18 & 31 \\
\hline $\begin{array}{c}\text { 28 Days } \\
\text { to 1 Year }\end{array}$ & 5 & 11 & 16 \\
\hline 3-5 Year & 2 & 3 & 5 \\
\hline \multicolumn{2}{|c|}{ Table 5. Relationship of Age and Renal Function } \\
\hline
\end{tabular}

\begin{tabular}{|c|c|c|}
\hline $\begin{array}{c}\text { Type of } \\
\text { Surgery Performed }\end{array}$ & $\begin{array}{c}\text { No. of } \\
\text { Patients }\end{array}$ & Description \\
\hline $\begin{array}{c}\text { Cystoscopic } \\
\text { fulguration of PUV }\end{array}$ & 54 & $\begin{array}{c}\text { Primary } \\
\text { Fulguration }\end{array}$ \\
\hline $\begin{array}{c}\text { Cystoscopy + closure } \\
\text { of Vesicostomy }\end{array}$ & 6 & $\begin{array}{c}\text { Same Sitting } \\
\text { (Vesicostomy Outside) }\end{array}$ \\
\hline \multicolumn{2}{|c|}{ Table 6. Type of Surgery performed } \\
\hline
\end{tabular}

\begin{tabular}{|c|c|c|}
\hline Complications & $\begin{array}{c}\text { No of } \\
\text { Patients }\end{array}$ & $\begin{array}{l}\text { Treatment } \\
\text { Required }\end{array}$ \\
\hline Transient Haematuria & 6 & $\begin{array}{c}\text { Spontaneously } \\
\text { Stopped+ iv Fluid }\end{array}$ \\
\hline Retention of Urine & 5 & Recatheterization \\
\hline Urethral Stenosis & 3 & Unilateral Dilatation \\
\hline UTI & 3 & I/V Antibiotics \\
\hline Incomplete Ablation & 2 & Refulguration \\
\hline Transient Incontinence & 1 & Spontaneous Recovery \\
\hline Persistent Uraemia & 2 & Referred for dialysis \\
\hline Death & 4 & - \\
\hline
\end{tabular}

\begin{tabular}{|c|c|c|c|c|}
\hline Prognosis & $\begin{array}{c}\text { Early } \\
\text { Cases }\end{array}$ & $\mathbf{\%}$ & $\begin{array}{c}\text { Late } \\
\text { Cases }\end{array}$ & $\%$ \\
\hline Resolution of Uraemia & 18 & $30 \%$ & 7 & $12 \%$ \\
\hline Resolution of VUR & 14 & $50 \%$ & 6 & 225 \\
\hline Recurrent UTI & 1 & $2 \%$ & 2 & $3 \%$ \\
\hline $\begin{array}{c}\text { Catching up of the Normal } \\
\text { Growth (Up to 30th Percentile) }\end{array}$ & 24 & $70 \%$ & 10 & $30 \%$ \\
\hline \multicolumn{4}{|c|}{ Table 8. Progress of Patients } \\
\hline
\end{tabular}

\section{DISCUSSION}

In recent decades, the immediate outcome of boys with PUV has improved continuously with the development of early diagnostic and treatment modalities. There is growing concern over the long term outcome of these children as 24 to $45 \%$ of them develop renal failure in childhood or adolescence. Unfavourable prognostic indicators include antenatal presentation before 24 weeks of intrauterine life, renal dysplasia, poor corticomedullary differentiation on ultrasonography, B/L vesicoureteric reflux (VUR) and persistence of high serum creatinine at 1 year of age. PUV is often suspected prior to birth on routine antenatal ultrasonography showing bilateral hydronephrosis and or large urinary bladder. This may lead to foetal morbidity and mortality mainly due to renal dysplasia and hypoplasia of lungs. ${ }^{9,10}$

In our study, only eight patients were suspected antenatally (13\%) on ultrasound showing bilateral hydronephrosis and large distended urinary bladder, later confirmed on voiding cystourethrogram (VCUG) after birth. More awareness is needed on the part of the ultrasonologists about detecting the problem antenatally. At birth, patients may present with palpable kidney, retention of urine with palpable bladder or renal failure. Older children presented with UTI in the form of recurrent fever, poor urinary stream, dribbling, straining to urinate and palpable urinary bladder and kidney. Ultrasonography helps in diagnosis of PUV, but the gold standard is VCUG. VCUG is considered the diagnostic study of choice for the evaluation of posterior urethral valve. VCUG confirms the PUV and also determines VUR. In our study 28 cases $(47 \%)$ had VUR. We found VUR more in our 
patients than other studies possibly as they were referred late. ( $40 \%$ after the age of 3 years) whereas most of the cases in western literature are diagnosed antenatally or in younger age. Among the patients, VUR is commonly unilateral and more commonly found on the left side (43\%). Incidence of right sided VUR was $14 \%$ and bilateral VUR was again $43 \%$. Following valve ablation, the severity of VUR may decrease in $7 \%$ or resolve completely in $33 \%$ of cases, and this improvement is more likely in those presenting as neonates or during infancy. Persistent VUR (4 patients), especially high grade and bilateral, after successful valve ablation is associated with poor long term renal outcome and one of the poor prognostic indicators identified by Parkhouse et al. There is no longer the trend to perform the ante-reflux procedures in boys with PUV, s failure rates associated with this approach are high.

Affected neonates usually do not tend to have any other system disorder other than the associated renal dysfunction; however, a higher incidence of cryptorchidism compared to the normal population has been noted. However, in our study, among 60 children, 4 had high variety of anorectal malformation (rectovesical fistula -1 , recto bulbar fistula -2 , perineal fistula - 1), 6 had distal penile hypospadias, 2 had undescended testis, both are on the left side (Canalicular variety).

Majority of neonates presenting with posterior urethral valve will demonstrate bilateral hydroureteronephrosis. This is often seen to improve with initial catheterization, but may temporarily worsen due to functional obstruction at the level of the VUJ by the thickened bladder wall that collapses, pinching off the ureteric orifices following catheterization and decompression. It is important to recognize this phenomenon and occasionally this can result in anuria that last for 24 to 48 hours. The obstruction spontaneously resolve within 48-72 hours and is usually followed by post obstructive diuresis. In our study, the non VUR, Hydroureteronephrosis (HDUN) patients (32 patients) slow but unobstructed drainage was persistent in 4 patients at 1 year, 6 were poorly functioning kidney. Cystoscopy serves both diagnostic and therapeutic purposes. Appropriate infant sized cystoscope ( $4.5 \mathrm{~F}$ ) is needed to avoid injury to urethra. Multiple techniques have been described for ablating the valves. Disruption of the obstructing membrane by blind passage of a valve hook is now out dated. Valve should be disrupted under direct vision by cystoscopy using an endoscopic loop, Bugbee electro-cauterization, and resectoscope or laser fulguration. The objective is to relieve the obstruction by cutting the valves at 12, 5 and $70^{\prime}$ clock position in least traumatic fashion to avoid the urethral injury which may result in the secondary urethral stricture or damage to sphincter mechanism. We performed check cystoscopy regularly at 6 weeks to assess adequacy of primary fulguration and proceed for further fulguration if there is residual valves. In our study six patients required repeat fulguration.

Temporary vesicostomy is done in younger patients as urethra may be too small for available cystoscope. It will stabilize the patients of PUV and improve the renal function and size of ureters. ${ }^{11,12}$ Nowadays fulguration of PUV is done directly without prior diversion of urine. ${ }^{13,14}$

PUV is the second most common cause of CRF in children. In one study, it was reported in $23 \%$ of cases, while it was seen in 7\% cases in Guys' hospital, UK series. It was present in $10 \%$ of our cases and almost all the cases who presented between 3-5 years (8\%) had chronic renal failure.

In spite of successful ablation of valves, 4 patients have persistent VUR and elevated creatinine value and required diversion in the form of loop ureterostomy. In our study 4 patients died (Pulmonary insufficiency-2, metabolic abnormalities - 2) in spite of all sorts of management.

In literature, approximately $10-15 \%$ of children undergoing renal transplant have PUV. So long term treatment of bladder dysfunction may be required after fulguration.

\section{CONCLUSION}

Delay in the diagnosis and management of PUV leads to renal damage resulting in End Stage Renal Disease. An increasing number of cases are diagnosed antenatally but prenatal intervention does not appear to confer a benefit in the long term outcome of renal function. Primary valve ablation is the recommended treatment of choice with diversion being reserved for specific individual cases.

A significant number of boys with PUV will develop chronic kidney disease. Structured follow up aims to prevent upper tract deterioration, prevent urinary tract infection, maximize growth and allow surveillance for bladder dysfunction. Antenatal detection, counselling of the couple regarding the poor outcome if there is oligohydramnios, early fulguration before 28 days, renal growth, tubular function, bladder functions, optimization of renal protective measures and surgical interventions as and when required on follow up are important in the management of all children with posterior urethral valve. Comprehensive care should be the rule by a team comprising of paediatricians, paediatric surgeon, paediatric nephrologists for prompt diagnosis and management of upper and lower urinary tract of these children. This will go a long way in reno-protection and delaying the occurrence of kidney failure in children with corrected posterior urethral valve. It also helps in early planning of renal replacement therapies in children with progressive renal insufficiency.

\section{REFERENCES}

[1] Stephens FD. Congenital intrinsic lesions of posterior urethra in congenital malformation of urinary tract. Praeger publishers, New York 1983:95.

[2] Elder JS, Duckett JW. Management of the fetus and neonates with hydronephrosis detected by prenatal ultrsonography. Pediatr Annals 1988;17(1):19-28.

[3] Rasheed K, Nazir Z, Moazam F. Posterior urethral valves in infants. Role of vesicostomy in preserving renal function. First International symposium of the institute of urology and transplantation 1994:F4.

[4] Hinchliffe SA, Chan YF, Jones H, et al. Renal hypoplasia and postnatally acquired cortical loss in children with vesicoureteral reflux. Pediatr Nephrol 1992;6(5):439-44.

[5] Colodny AH. In utero diagnosis of urologic abnormalities. Dialogues Pediatr Urol 1983;66:11.

[6] Dahmane FD, Dommergues M, Muller F, et al. Development of human fetal kidney in obstructive uropathy: correlations with ultrasonography and urine biochemistry. Kidney Int 1997;52(1):21-32. 
[7] Jamro S. Chronic renal failure. Dissertation for FCPS (CPSP) 1994.

[8] Pieretti RV. The mild end of clinical spectrum posterior urethral valves. J Pediatr Surg 1993;28(5):701-4.

[9] Tolmatschew N. A case of semilunaren flaps of the urethra and vergrisserter vesicula prostatice. Archiv Path Anat 1870;11:348.

[10] Close CE, Carr MC, Burns MW, et al. Lower urinary tract changes after early valve ablation in neonates and infants: is early diversion warranted? J Urol 1997;157(3):984-8.
[11] Borzi PA, Beasley SW, Fowler R. Posterior uretrhral valves in non-twin siblings. Br J Urol 1992;70(2):201.

[12] Murphy JP, Gatti JM. Abnormalities of the urethra, penis and scrotum. In: Grosfeld JL, O'neill JA, Fonkalsrud EW, (eds). Pediatric surgery. $6^{\text {th }}$ edn. Ohiladelphia: Mosby Elsevier 2006:1899-910.

[13] Dewan PA, Zappla SM, Ransley PG, et al. Endoscopic reappraisal of the morphology of congenital obstruction of the posterior urethra. Br J Urol 1992;70(4):439-44.

[14] Blews DE. Sonography of the neonatal gastrourinary tract. Radiol Clin North A 1999;37(6):1999-208. 